\title{
EXPOSIÇÃO SOLAR E SUPLEMENTAÇÃO DE VITAMINA D EM LONGEVOS DURANTE A PANDEMIA DE COVID-19
}

Cintia Cristina Sulzbach; Escola de Medicina da PUCRS, Projeto de extensão Atenção Multiprofissional ao Longevo (AMPAL), Porto Alegre, Brasil; cintia.sulz@gmail.com

Renata Breda Martins; Escola de Medicina da PUCRS, Projeto de extensão Atenção Multiprofissional ao Longevo (AMPAL), Porto Alegre, Brasil; nutrirenatamartins@gmail.com

Liziane da Rosa Camargo; Escola de Medicina da PUCRS, Projeto de extensão Atenção Multiprofissional ao Longevo (AMPAL), Porto Alegre, Brasil; lizicamargo.nutri@gmail.com

Ângelo José Gonçalves Bós; Escola de Medicina da PUCRS, Projeto de extensão Atenção Multiprofissional ao Longevo (AMPAL), Porto Alegre, Brasil; angelo.bos@pucrs.br

\section{RESUMO}

Introdução: A deficiência de vitamina D é mais prevalente em nonagenários e centenários, tendo risco elevado para condições como: osteoporose, sarcopenia, deficiência imunológica e mortalidade. A fonte mais disponível da vitamina é a pele, em resposta à exposição solar. Entretanto, o isolamento social pelo COVID-19 pode ter influência em relação à exposição solar. Objetivo: Verificar a frequência de exposição solar e suplementação de vitamina $\mathrm{D}$ em nonagenários e centenários durante a pandemia de COVID-19. Métodos: Participaram nonagenários e centenários do projeto Atenção Multiprofissional ao Longevo que envolveu uma amostra representativa contactada por telefone entre março e agosto de 2020. As variáveis investigadas foram sociodemográficas, frequência de exposição solar e suplementação de vitamina D. Resultados: Responderam 59 nonagenários e centenários, $78 \%$ do sexo feminino, com média de idade $96 \pm 3,8$ anos, $73 \%$ viúvos e $76 \%$ brancos. A maioria (68\%) não reduziu a exposição solar no período de isolamento social, sendo que $51 \%$ tem se exposto ao sol 5 ou mais vezes/semana e $12 \%$ tem realizado suplementação com vitamina D. Em relação ao sexo, identificou-se aumento à exposição solar em $7 \%$ das mulheres, já nos homens houve redução de 23\%. Conclusão: Mesmo com o isolamento social, notou-se que, no geral, os participantes se expuseram ao sol apresentando frequência adequada, no entanto, no sexo masculino essa exposição foi menor.

Palavras-chaves: Vitamina D; Infecções por Coronavirus; Suplementos Nutricionais; Saúde do Idoso; Saúde Pública. 